\title{
Rare Complication of Stereotactic Guide-Wire Localization of Nonpalpable Breast Lesions: Breakdown of the Wire-The First Series From Turkey Involving 20 Case Analyses
}

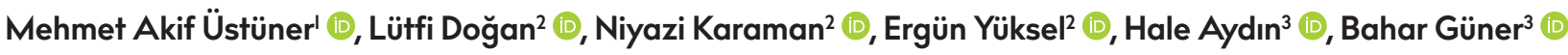 \\ 'Departman of Gastroenterologic Surgery, Türkiye Yüksek ihtisas Training and Resarch Hospital, Ankara, Turkey \\ ${ }^{2}$ Departman of General Surgery, Dr. Abdurrahman Yurtaslan Ankara Oncology Training and Resarch Hospital, Ankara, Turkey \\ ${ }^{3}$ Departman of Radiology, Dr. Abdurrahman Yurtaslan Ankara Oncology Training and Resarch Hospital, Ankara, Turkey
}

ORCID IDs of the authors: M.A.Ü. 0000-0003-4087-555X; L.D. 0000-0002-3834-09II; N.K. 0000-000I-9875-70I7; E.Y. 0000-000I-8425I365; H.A. 0000-0002-4789-464I; B.G. 0000-0002-9855-6992.

Cite this article as: Üstüner MA, Doğan L, Karaman N, Yüksel E,Aydın H, Güner B. Rare Complication of Stereotactic Guide-Wire Localization of Nonpalpable Breast Lesions: Breakdown of the Wire-The First Series From Turkey Involving 20 Case Analyses. Cyprus $J$ Med Sci 2019; 4(2): 90-4.

\section{BACKGROUND/AIMS}

In cases wherein percutaneous biopsy cannot be performed via imaging, a wire-guided breast biopsy is used for the diagnosis of nonpalpable breast cancer. Although known as a safe procedure, complications may develop rarely. In this study, we analyzed 20 cases of instances of guide-wire breakdown that occurred when the procedure was performed.

\section{MATERIAL and METHODS}

We retrospectively analyzed 818 patients with guide wire-localized breast lesions between January 2015 and June 2017 from electronic files at our hospital.

\section{RESULTS}

Wire breakdown occurred in 20 patients. Although the guide wire broke down in the breast specimen of 15 patients (75\%), it broke apart from the specimen in 5 patients (25\%); 3 of these 5 wires were noticed intraoperatively in the remaining tissue and were removed by reexcision. The remaining 2 wires were noticed using imaging methods during the postoperative period and removed by inserting a second wire. The guide-wire indications in these 20 patients were as follows: microcalcification in 14 (70\%); structural distortion in 3 (I5\%); and focal, asymmetrical area in $3(15 \%)$ patients. Pathology results revealed that the breast specimens were benign in $13(65 \%)$ patients and malignant in 7 (35\%) patients.

\section{CONCLUSION}

Although guide-wire breakdown was rarely reported in wire-marked breast biopsies, the frequency is not fully known. Because the wire may breakdown inside the specimen, it can also be found in the remaining breast tissue. Residual wire should be removed by coordinating with the radiologist to prevent possible complications.

Keywords: The wire-guided localization, wire breakdown, nonpalpable breast cancer

\section{INTRODUCTION}

Nonpalpable breast cancer became a common finding on mammograms taken for screening asymptomatic women (I). Approximately 25\%-35\% breast cancers consist of nonpalpable breast lesions (2). These lesions are observed to have a linear configuration, asymmetrical density, and structural distortion, and more frequently, they are seen as microcalcification and are classified as BIRADS 4-5 (2). For this reason, the lesions have to be excised and diagnosed. The wire-guided localization (WGL) technique was first described by Dodd et al. (3) in 1965. In this technique, the lesion in the breast is marked with a thin wire under the guidance of ultrasound or mammography, and the marked area is excised surgically. The excised tissue is sent to the radiology department for confirmation that the lesion has been removed, and the surgical procedure is terminated after this is confirmed. By this method, breast cancer can be diagnosed early, the size of the excised specimen for biopsy can be reduced, and simultaneously, bad cosmetic results can 
be prevented (4). As any other interventional processes, this process can also lead to some complications. Vasovagal reflex may develop during wire insertion, pneumothorax can occur, the location may change after insertion, and although rarely, the wire can breakdown (5).

If the wire breaks and stays in the breast long enough, the metal induces carcinogenesis, and nickel complexes cause chromosomal damage, activating signaling pathways and altering the cell genetics, which can cause cancer. Conversely, if the patient sees the wire broken during control mammography, it can lead to medicolegal and psychological problems. We were sued by one of our patients for this reason; therefore, caution is important.

In this study, we analyzed 20 cases in which the wire broke down during the procedure.

\section{MATERIAL and METHODS}

We analyzed 818 patients with guide wire-localized breast lesions between January 2015 and June 2017, and this was approved by the Ethics Committee of our hospital. The surgical notes, imaging methods, pathology reports, and medical history were analyzed by a retrospective search of patients records. Data on complications during the procedure were obtained via patient observation forms.

The IBM Statistical Package for Social Sciences version 20.0 for Windows (IBM Corp.; Armonk, NY, USA) was used to record the data.
An approval was received for this study from the local Ethics Committee of Dr. Abdrurrahman Yurtaslan Oncology Training and Research Hospital ( $\mathrm{AOH}$ II/3/2017). Written informed consent was obtained from patients who participated in this study.

\section{RESULTS}

Overall, there were 20 instances of wire breakdown, proven by imaging methods, which were detected from 818 cases in an approximately 30-month period. A guide wire was introduced under mammographic guidance in all cases. The mean age of the patients was calculated as 51.3 (range, 4I-7I). Although the guide wire broke down in the breast specimen of 15 patients $(75 \%)$, it broke apart from the specimen in 5 patients (25\%) (Table I). The wires that broke down in the specimens were detected by radiological examination of tissue samples obtained during surgery (Figure I); 3 of the 5 wires that broke down out of the specimen were noticed intraoperatively by manual examination of lumpectomy cavity and were removed by re-excision (Figure 2). The remaining 2 wires were noticed via imaging methods in the postoperative period (I year later) and removed by inserting a second wire (Figure 3). Guide-wire indications in the 20 patients were as follows: microcalcification in 14 (70\%); structural distortion in 3 (I5\%); and focal, asymmetrical area in $3(15 \%)$ patients. Pathology results revealed that breast specimens were benign in 13 (65\%) patients and malignant in 7 (35\%) patients. Although 5 patients with malignant results underwent surgery, I was administered prophylactic chemotherapy and I was lost to follow-up.

\begin{tabular}{|c|c|c|c|c|}
\hline Patient no. & Age & Wire indication & Pathology & The site of breakdown \\
\hline 1 & 48 & Microcalcifications & DCIS, Grade 3 & In specimen \\
\hline 3 & 47 & Microcalcifications & Atypical ductal hyperplasia & In specimen \\
\hline 4 & 47 & Microcalcifications & DCIS, Grade 3 & In specimen \\
\hline 6 & 47 & Focal asymmetric area & Fat necrosis & In specimen \\
\hline 7 & 55 & Microcalcifications & Fibrocystic change & In specimen \\
\hline 8 & 60 & Microcalcifications & DCIS, Grade 2 & In specimen \\
\hline 9 & 53 & Microcalcifications & Adenosis & In specimen \\
\hline 13 & 49 & Microcalcifications & Fibrocystic change & In specimen \\
\hline 14 & 71 & Microcalcifications & Fibrocystic change & In specimen \\
\hline 15 & 41 & Microcalcifications & Adenosis & In specimen \\
\hline 16 & 44 & Microcalcifications & Ductal ectasia & Out of specimen \\
\hline $17^{*}$ & 45 & Focal asymmetric area & Adenosis & Out of specimen \\
\hline 18 & 46 & Focal asymmetric area & LCIS & Out of specimen \\
\hline 19 & 57 & Microcalcifications & Micropapillary cancer, Grade 2 & Out of specimen \\
\hline $20^{*}$ & 57 & Structural distortion & Fat necrosis & Out of specimen \\
\hline
\end{tabular}




\section{DISCUSSION}

Because palpable breast cancer is usually symptomatic and patients report to the hospital frequently, it is more easily detected. However, nonpalpable breast cancers are usually asymptomatic, and as long as there is no nipple discharge, pain, or erythema, they are usually diagnosed using radiological screening methods. The incidence of nonpalpable breast lesions has increased with the widespread employment of mammography screening programs. Approximately 15\%-20\% of these lesions are malignant; therefore, those that are radiologically suspicious must be excised (6). The most commonly used methods for the excision of nonpalpable lesions are percutaneous biopsy, radio-guided occult lesion localization (ROLL), and WGL; percutaneous biopsy is the gold standard. ROLL was reported as a new method

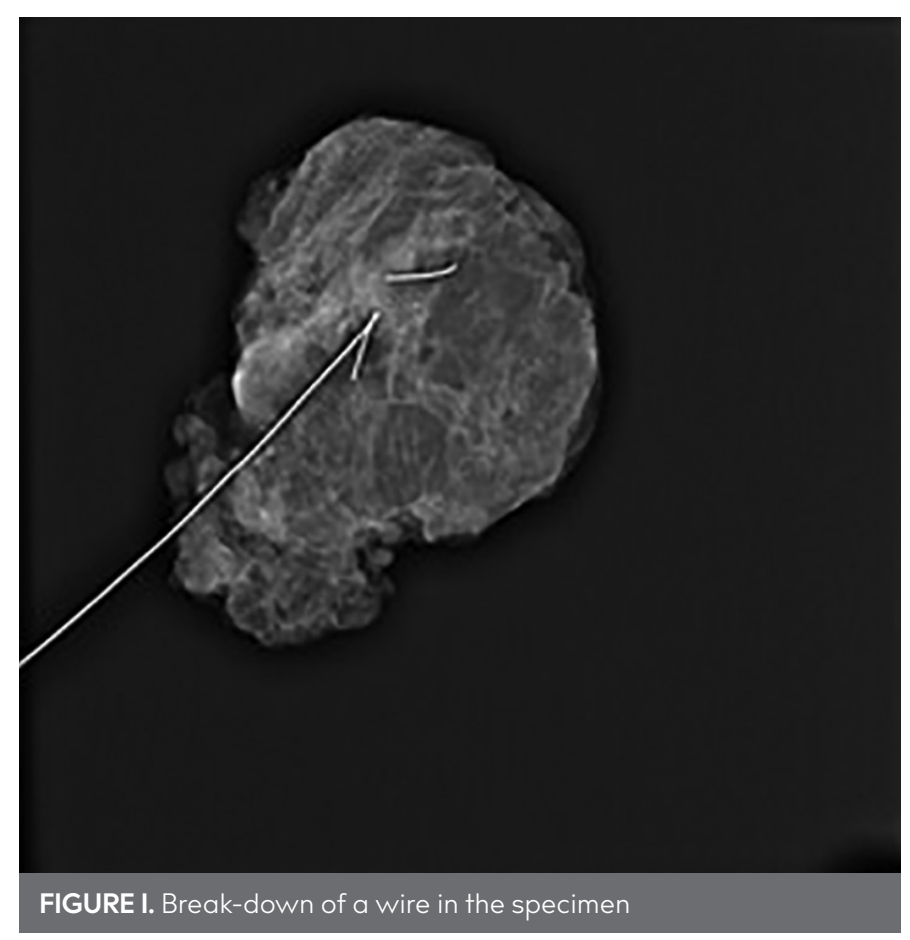

in 1998, in which a radiopharmaceutical drug is injected into the tumor, and the lesion is removed via excisional biopsy using a gamma probe (7). In the WGL method, the region of the lesion is surgically excised using a guide wire positioned under the guidance of ultrasound or mammography (8). Certain criteria must be adhered to when a wire is placed by a radiologist. Although Abrahamson suggested that the wire should be placed within 5 $\mathrm{mm}$ of the lesion to increase the success rate, Sagutti suggested that the wire should be advanced through the lesion to a depth of $<1 \mathrm{~cm}(8,9)$. General or local anesthesia may be preferred during the surgery. General anesthesia is preferred for patients with deep-seated lesions and those with large breasts (4). In our series, 18 patients were operated under local and 2 under general anesthesia. Two different wire types are used in WGL: stainless steel and nitinol (nickel and titanium). Results of in vitro study has revealed that metal induces carcinogenesis, and nickel complexes cause chromosomal damage, activate signaling pathways, and alter cell genetics (I0). We used stainless steel wires (Anbao, USA, 20G/10 cm) for all our patients. WGL has some preoperative and postoperative disadvantages. It is difficult to place the guide wire in dense breasts (II); 16 (80\%) of our patients had dense breasts.

Furthermore, the wire may dislocate during surgery. As the surgeon removes the healthy tissue to find the lesion, more tissue than necessary might be removed. In addition, the wire may cause pneumothorax by migration or by the racquet effect (the wire can be pulled by the pectoral muscle to cause pneumothorax). The guide wire can be broken down during surgery (5, 12). The broken part of the wire should be removed when it is noticed. Forgotten wires can be observed later during control mammography. In literature, guide-wire breakdown was reported at a rate of $0 \%-3 \%$ (12). In our series, 20 (2.5\%) instances of guide-wire breakdown among 818 cases in the last 2.5 years were noted, and this ratio is compatible with the one in the literature. Handa et al. (I3) reported low-grade adenosquamous carcinoma in the tissues around the broken-down wire in a pa-

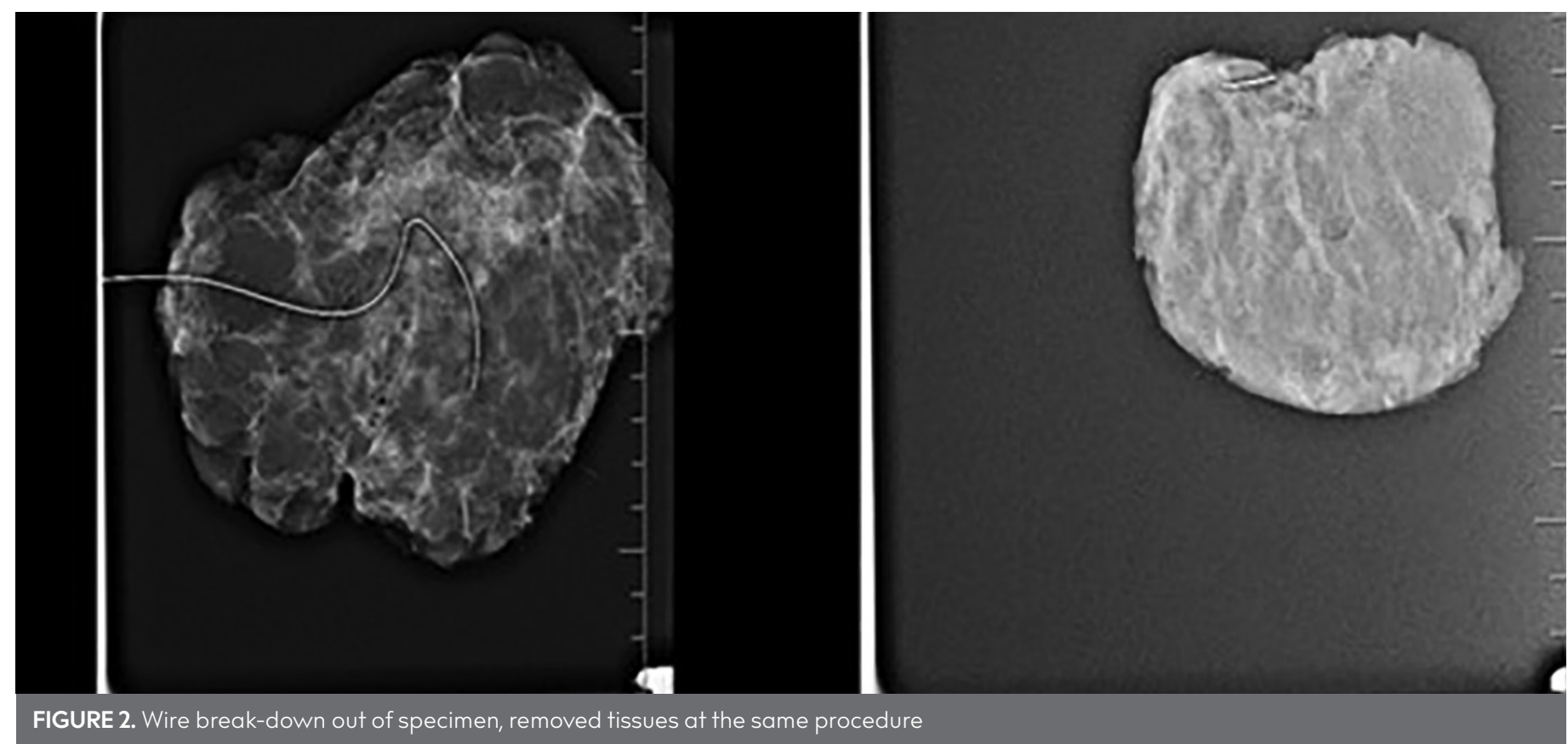




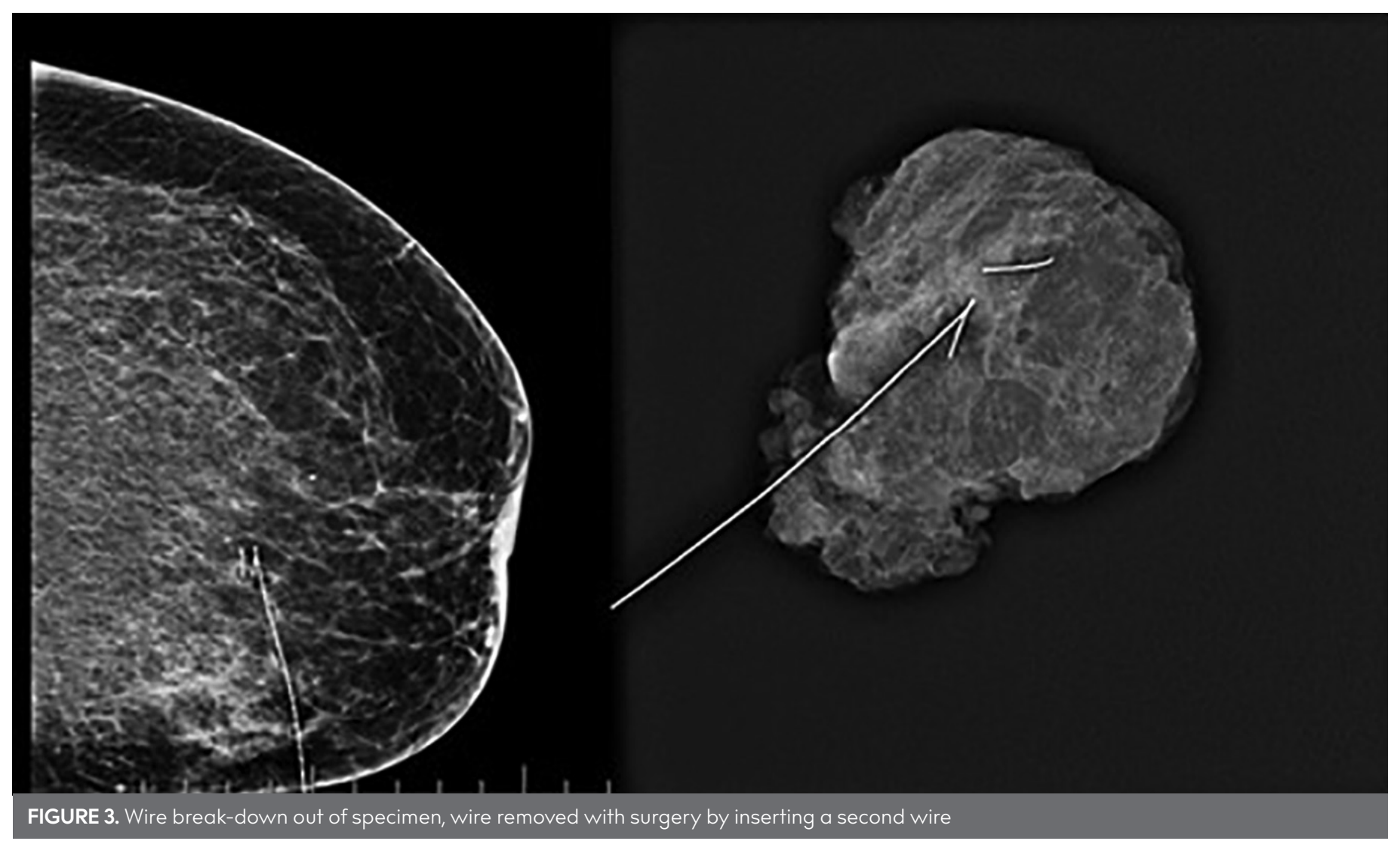

tient who underwent WGL 10 years ago. The pathology report was evaluated as fat necrosis in two cases that we removed I year later, malignancy was not detected. In a study by Monterey et al. (12), 8 broken-down wires were reported on 32,473 mammograms. The length of these wires ranged from 0.7 to $4.2 \mathrm{~cm}$. The remaining wires are usually asymptomatic and can cause pain by movement. A second wire localization may be necessary to remove the residual broken wire (13). In our series, a second wire localization was necessary in 2 patients (Table I, patients 17 and 20). Results of primary and secondary biopsies revealed that the specimens of these patients were benign. The remaining wires may stay in the same region or migrate to the infraclavicular fossae, subcutaneous tissue, cervical muscles, and even to the contralateral axillae $(14,15)$. Homer suggested periodic mammography owing to the possibility of wire migration in patients who do not agree to undergo surgery (16). As long as the residual wires do not penetrate the pectoral muscle, they usually do not create a medical problem. However, the patient may be in trouble because she does not know the kind of problems it may cause in the breast; therefore, medicolegal problems may occur (I3). Consequently, the radiology and surgical team should work in coordination to improve quality standards while performing WGL, especially in reference centers, such as our hospital, where breast surgery is often performed. The direction and distance of the wire inserted by the radiologist during the preoperative period should be presented in a 3D format. In cases of doubt, intraoperative re-excision should be performed and broken wire should not be left behind. The patient should be referred to the surgical team for the wires seen in the post-operative mammograms. If necessary, surgery must be performed under general anesthesia to increase the comfort of the patient and surgeon.
At the end of the procedure, surgeons should control the cavity When a wire fracture is noticed during the postoperative period, the patient should be informed to avoid medicolegal problems, and the wire should be removed if possible. If not, the patient should be followed up by mammography to prevent wire migration.

Ethics Committee Approval: Ethics committee approval was received for this study from Dr.Abdurrahman Yurtaslan Oncology Training and Resarch Hospital (Approval Date: 03.II.2017, Approval Number: 2017|l8).

Informed Consent: Written informed consent was obtained from patients who participated in this study.

Peer-review: Externally peer-reviewed.

Author contributions: Concept - A.Ü., L.D., N.K.; Design - A.Ü., L.D.; Supervision - A.Ü., H.A., B.G.; Resource - A.Ü., B.G., H.A.; Materials - E.Y., H.A., B.G.; Data Collection and/or Processing - E.Y., H.A., A.Ü.; Analysis and/or Interpretation - A.Ü., N.K., B.G.; Literature Search - A.Ü., E.Y., H.A.; Writing - A.Ü., L.D., N.K.; Critical Reviews - A.Ü., L.D., N.K.

Conflict of Interest: The authors have no conflicts of interest to declare.

Financial Disclosure: The authors declared that this study has received no financial support.

\section{REFERENCES}

I. Ocal K, Dag A, Turkmenoglu O, Gunay EC, Yucel E, Duce MN. Radioguided occult lesion localization versus wire-guided localization for non-palpable breast lesions: randomized controlled trial. Clinics (Sao Paulo) 20Il; 66: 1003-7. [CrossRef]

2. Dogan L, Gulcelik MA, Yuksel M, Uyar O, Reis E. Wire-guided localization biopsy to determine surgical margin status in patients with non-palpable suspicious breast lesions. Asian Pacific J Cancer Prev 2012; 13: 4849-92. [CrossRef] 
3. Dodd GD, Fry K, Delany W. Pre-op localization of occultcarcinoma of the breast. In: Nealon TF, ed. Management of the patient with cancer. Philadelphia: Saunders 1965: 88-II3.

4. Derici H, Tansuğ T, Nazlı O, Bozdağ AD, Koç O, Varer M, et al. Stereotactic wire localization and surgical excision of non-palpabl breast lesions. J Breast Health 2007; 3: I.

5. Hanora MA, Abdel Hamid AEM, Mehanna AA, Hamed YS, Maghraby HK, IbrahiM RM. Role of imaging guided wire localization of nonpalpable breast lesions: Effect of localization accuracy on surgical outcome and histopathological safety margins. Biolife 2015; 3: 883-8.

6. Postma EL, Witkamp AJ, van den Bosch MA, Verkooijen HM, van Hillegersberg R. Localization of nonpalpable breast lesions. Expert Rev Anticancer Ther 2011; I: 1295-302. [CrossRef]

7. Luini A, Zurrida S, Galimberti V, Paganelli G. Radioguided surgery of occult breast lesions. Eur J Cancer 199; 34: 204-5.

8. Saguatti G, Oste G, Teggi S. Breast tissue diagnosis in Alfonso A $M$. The out patient breast clinic; aiming of best practice. Springer Switzerland 2015; 130: 149. [CrossRef]
9. Ngô C, Pollet AG, Laperrelle J, Ackerman G, Gomme S, Thibault F, et al. Intraoperative ultrasound localization of nonpalpable breast cancers. Ann Surg Oncol 2007; 14: 2485-9. [CrossRef]

10. Salnikow K, Zhitkovich A. Genetic and epigenetic mechanisms in metal carcinogenesis and cocarcinogenesis: nickel, arsenic, and chromium. Chem Res Toxicol 2008; 21: 28-44. [CrossRef]

II. Davis PS, Wechsler RJ, Feig SA. Migration of breast biopsy localization wire. Am J Radiol 1983; 141: 929-30.

12. Montrey JS, Levy JA, Brenner RJ. Wire Fragments After Needle Localization. AJR Am J Roentgenol 1996; 167: 1267-9. [CrossRef]

13. Handa P, Khader SN, Buchbinder SS, Guelfguat M. Low-Grade Adenosquamous Carcinoma of the Breast Developing Around a Localization Wire Fragment. Lab Med 2015: 46; 24I-7. [CrossRef]

14. Davis PS, Wechsler RJ, Feig SA, March DE. Migration of breast biopsy localization wire. AJR Am J Roentgenol 1988: 150: 787-8. [CrossRef]

15. Owen AW, Kumar EN. Migration of localizing wires used in guided biopsy of breast. Chin Radiol 1991: 43: 25I. [CrossRef]

16. Homer MJ. Migration of the localization wire (letter). AJR Am J Roentgenol 1988; 151: 615-6. [CrossRef] 